\title{
Polar solvent effects on tartaric acid binding by aromatic oligoamide foldamer capsules
}

\author{
Nagula Chandramouli, ${ }^{a, b}$ Mohammed Farrag El-Behairy, ${ }^{a, b, c}$ Guillaume Lautrette, ${ }^{a, b}$ Yann \\ Ferrand ${ }^{*}, a, b$ and Ivan $\mathrm{Huc}^{*}, a, b$
}

\begin{abstract}
Aromatic oligoamide sequences able to fold into single helical capsules were functionalized with two types of side chains to make them be soluble in various solvents such as chloroform, methanol or water and their propensity to recognize tartaric acid was evaluated. Binding affinities to tartaric acid and binding thermodynamics in the different media were investigated by variable temperature ${ }^{1} \mathrm{H}$ NMR and ITC experiments, the two methods giving consistent results. We show that tartaric acid binding mainly rests on enthalpically favourable polar interactions that were found to be sufficiently strong to be effective in presence of a polar aprotic solvent (DMSO) and even in pure methanol. Binding in water was very low. The stronger binding interactions were found to be more susceptible to the effect of competitive solvents and to be compensated by unfavourable entropic effects. Thus, the best host in less polar medium eventually was found to be the worst host in protic solvents. An interesting case of entropically driven binding was evidenced in methanol.
\end{abstract}

\section{Introduction}

The design of synthetic hosts that can recognize polar guests in polar media and in particular in water remains very challenging. ${ }^{1}$ This contrasts with many successful examples of artificial containers able to bind apolar guests in water as, for example, molecular capsules such as cavitand-based (hemi)carcerands, ${ }^{2}$ cryptophanes, ${ }^{3}$ capsules assembled through electrostatic interactions, ${ }^{4}$ self-assembled metallo-organic cages, ${ }^{5}$ cyclodextrins $^{6}$ or cyclophanes. ${ }^{7}$ While the binding of non-polar molecules in water is generally favoured by a strong hydrophobic component, the binding of polar molecules is influenced by solvent effects in ways that are complex and difficult to orchestrate..$^{1,8,9}$ Water is very effective at interacting with polar or charged groups through hydrogen bonds and, more often than not, the enthalpic term associated by the desolvation of host and guest are not well compensated by host-guest interactions, resulting in weaker binding in this solvent. However, entropic components arising from the release of bound solvent molecules upon desolvation sometimes plays a favourable role.

In recent years a novel class of synthetic receptors have emerged derived from artificial folded molecular strands, i.e. foldamers. ${ }^{10}$ Foldamers are inspired from biopolymers and exploit folding as a means to create cavities to accommodate guest molecules and control the spatial organization of recognition groups towards them. ${ }^{11}$ Because their chemical nature differs from that of peptides and nucleotides, foldamers may be expected to show properties and functions beyond the reach of their natural counterparts. In particular, aromatic oligoamides feature a combination of easy synthetic access, highly stable folded conformations in a wide range of solvents, ${ }^{12}$ and a high predictability of their folded structures using simple computational means. ${ }^{13}$

A number of synthetic receptors have been produced based on the aromatic amide backbone. ${ }^{14}$ We have been interested in an original capsule design as a novel class of helical containers able to completely surround their guests and isolate them from the external medium. These containers consist of a helix whose diameter is narrower at each extremity and wider in the centre creating a cavity (Figure 1). ${ }^{15}$ In these capsules, amide protons and heteroaromatic nitrogen atoms converge towards the cavity resulting in a polar environment suitable to bind to polar guests in apolar medium through multiple hydrogen bonds. ${ }^{16}$ For example, we showed that sequence $\mathbf{1}$ was able to encapsulate $\mathrm{D} / \mathrm{L}$ tartaric acid $\mathbf{5}$ with high affinity, selectivity and diastereoselectivity in weakly polar organic solvents. ${ }^{16 c}$ The lack of any gap in the helical capsule wall implies that guest complexation and release proceed via a partial unfolding of the helix that temporarily opens up a passage. ${ }^{17}$ This mechanism was shown to be relatively slow due to the high stability of the receptor structure.

While binding is high in solvents such as $\mathrm{CDCl}_{3}:\left[\mathrm{D}_{6}\right]-\mathrm{DMSO}$ 90:10 (vol/vol), we had no information about the extent to which it would withstand the presence of protic solvents that compete for hydrogen bond formation between host and guest. To answer that question, and to assess whether the current binding modes could be exploited for applications in water, we first had to face the synthetic challenge to synthesize analogues of 1 that would be soluble in methanol and water in the millimolar range. In the following, we report the successful synthesis of the first water soluble aromatic oligoamide helical foldamer capsules and the investigation of tartaric acid recognition thermodynamics in the presence of DMSO, methanol and water. We find that binding decreases in protic solvents but does not completely vanish in some cases, with $K_{a}$ values as high as $2000 \mathrm{~L} \mathrm{~mol}^{-1}$ in methanol and $20 \mathrm{~L} \mathrm{~mol}^{-1}$ in water. Entropy appears to play a favourable role in maintaining this binding level.

\footnotetext{
a. Univ. Bordeaux, CBMN (UMR 5248), Institut Européen de Chimie Biologie, 2 rue Escarpit 33607 Pessac, France

b. CNRS, CBMN (UMR), Pessac, France.

c. Medicinal and Pharmaceutical Chemistry Department, Pharmaceutical and Drug Industries Research Division, National Research Centre, 12622 Dokki, Giza, Egypt.
} 


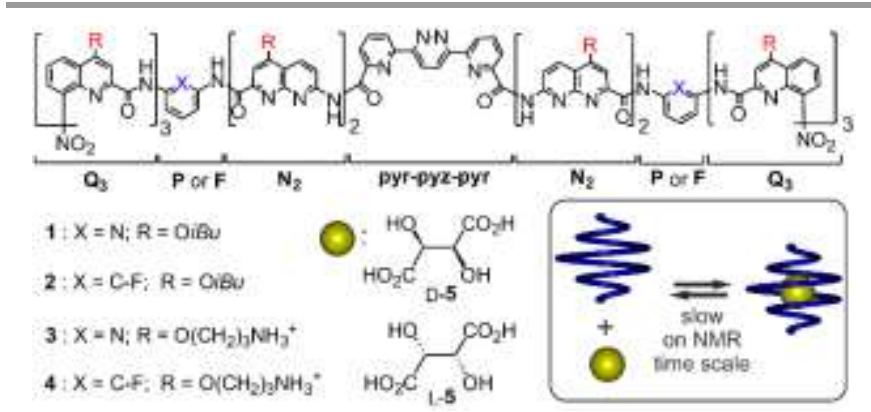

Fig. 1 (top) Formula of capsules 1, 2, 3 and 4. R group diverging from the helix and acting as solubilizing groups in either organic solvents or water are shown in red. Varying atoms pointing towards the centre of the cavity are denoted in blue; (bottom right) Schematic representation of the encapsulation of a guest molecule (yellow sphere: $\mathrm{D} / \mathrm{L}$ tartaric acid 5) into a helically folded capsule (blue).

\section{Results and discussion}

Design and synthesis. In early foldamer capsule designs, ${ }^{16}$ quinoline trimers $\left(\mathbf{Q}_{\mathbf{3}}\right)$ at each extremity of the sequences were introduced as end-caps of helix cavity and also to prevent dimerization into double helices. Pyridine monomers $(\mathbf{P})$ and naphthyridine dimers $\left(\mathbf{N}_{\mathbf{2}}\right)$ were then included in the sequences because their weaker curvature was expected to generate a cavity and because of their capacity to form hydrogen bonds, in particular to carboxylic acids. ${ }^{16 c, 18}$ The linear pyr-pyz-pyr central monomer was added so as to enlarge the capsule inner volume. ${ }^{16 \mathrm{c}}$ This led to the design of $\mathbf{1}$, which was shown to bind to tartaric acid with very high affinity and diastereoselectivity in organic solvents such as $\mathrm{CDCl}_{3}$ containing $10 \%\left[\mathrm{D}_{6}\right]$-DMSO. ${ }^{16 \mathrm{c}}$ In analogue 2 (Figure 1), the two pyridine units of $\mathbf{1}$ have been replaced by two fluorobenzene monomers. This sequence was produced in the context of iterative modifications of $\mathbf{1}$ aiming at improving its binding properties for other guests than tartaric acid in $\mathrm{CDCl}_{3}$. The synthesis of $\mathbf{2}$ and its binding properties for these other guests will be reported elsewhere.

To explore the extent to which molecular recognition using aromatic oligoamide capsules could be efficient in protic organic solvents or water, we considered new capsules $\mathbf{3}$ and $\mathbf{4}$ that carry water solubilising ornithine-like side chains instead of the lipophilic isobutoxy side chains of $\mathbf{1}$ and $\mathbf{2}$. For this purpose, we prepared both the previously described 8-amino-2quinoline-carboxylic acid monomer having a Boc protected 3aminopropoxy side chain ${ }^{19}$ and a new 7-amino-4-(3-(tertbutoxycarbonylamino)propoxy)-1,8-naphthyridine-2-carboxylic acid monomer (Scheme 1). Its preparation first involved the introduction of a Boc protected aminopropoxy side chain on naphthyridone 6 via a Mitsunobu reaction (65\%). Fortunately, the acetamido group of $\mathbf{7}$ could be methanolized using a stoichiometric amount of $\mathrm{H}_{2} \mathrm{SO}_{4}(0.5$ equiv.) in the presence of the Boc group (66\%). This reaction presumably proceeds via the protonation of the slightly more basic position 8 of the naphthyridine which increases the electrophilicity of the acetyl group and its reactivity towards methanol while conditions remain moderately acidic, thus preventing Boc cleavage. Then, amine $\mathbf{8}$ was protected with a Teoc group (2-(trimethylsilyl)ethyl carbamabate) using 4-nitrophenyl-2-(trimethylsilyl)ethyl carbonate (90\%). The methyl ester of 9 was quantitatively saponified to give naphthyridine acid 10 (99\%). Aminonaphthyridine benzyl ester $\mathbf{1 1}$ was obtained by a transesterification of the methyl ester of $\mathbf{8}$ using a large excess of benzyl alcohol and base (80\%).

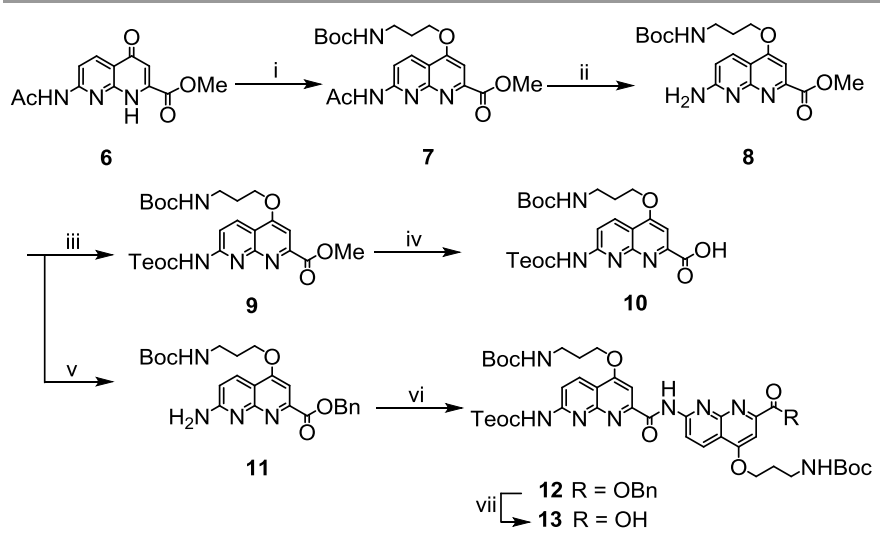

Scheme 1. Synthesis of naphthyridine derivatives bearing protected ornithine side chains. (i) $\mathrm{PPh}_{3}$, diisopropylazodicarboxylate, $\mathrm{N}$-(tert-butoxycarbonyl)-3-aminopropanol (65\%); (ii) $\mathrm{H}_{2} \mathrm{SO}_{4}, \mathrm{MeOH}$ (66\%); (iii) 4-Nitrophenyl 2-(trimethylsilyl)ethyl carbonate, $\Delta$ (90\%); (iv) $\mathrm{NaOH}$ (99\%); (v) BnOH, $\mathrm{Et}_{3} \mathrm{~N}$ (80\%); (vi) 10, PyBOP, DIEA (86\%); (vii) Pd/C, $\mathrm{H}_{2}$ (98\%).
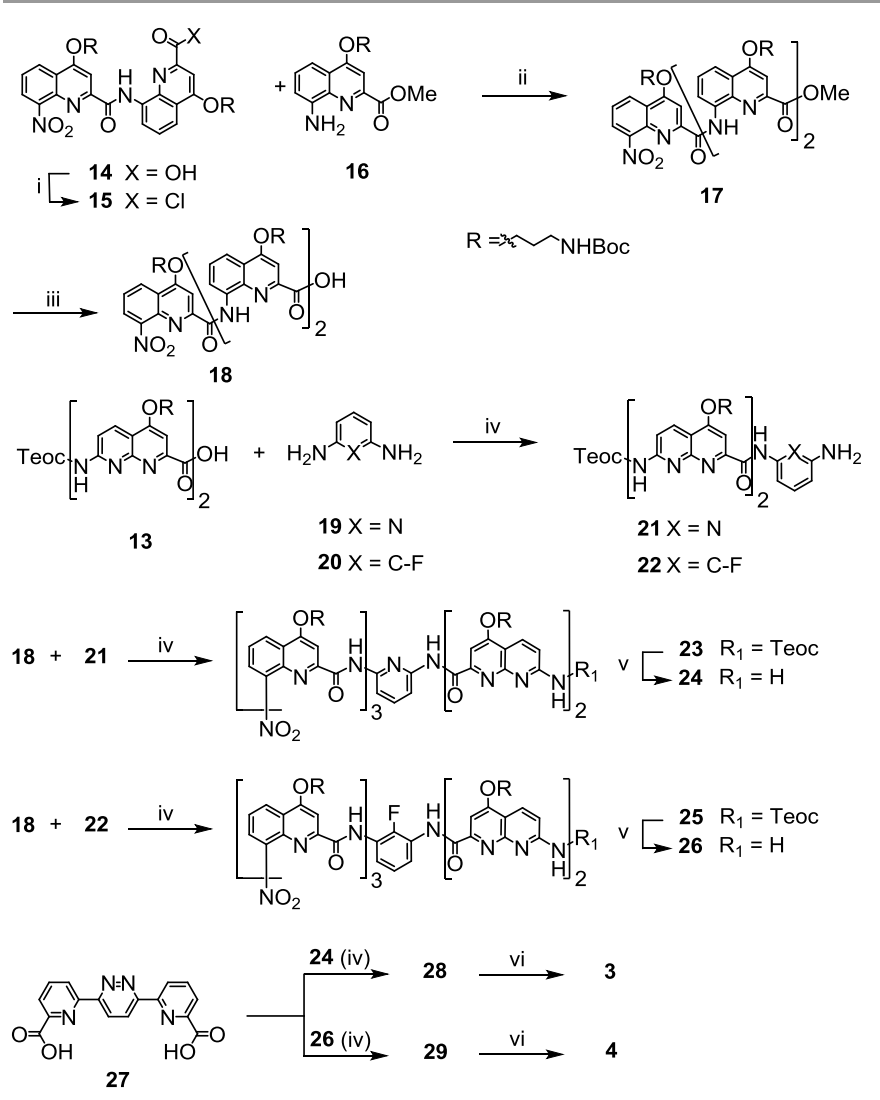

Scheme 2. Synthesis of water soluble oligomers 3 and 4. (i) 1-Chloro- $N, N, 2$-trimethyl-1propenylamine; (ii) DIEA; (iii) $\mathrm{NaOH}$; (iv) PyBOP, DIEA ; (v) TBAF; (vi) TFA.

As described earlier for organic soluble counterpart $1,{ }^{16 \mathrm{c}}$ a hexameric hemicapsule $\mathrm{O}_{2} \mathbf{N}-\mathbf{Q}_{3} \mathbf{P N}_{\mathbf{2}}$-Teoc $\mathbf{2 3}$ bearing Boc protected aminopropoxy side chains was synthesized in a 
convergent manner via the coupling of a $\mathrm{O}_{2} \mathrm{~N}-\mathrm{Q} 3-\mathrm{CO}_{2} \mathrm{H}$ segment with the amino group of $\mathrm{H}_{2} \mathrm{~N}-\mathrm{PN}_{2}$-Teoc using PyBOP (Scheme 2). A second hemicapsule $\mathrm{O}_{2} \mathrm{~N}-\mathbf{Q}_{3} \mathbf{F N}_{2}$-Teoc $\mathbf{2 5}$ was obtained using the same strategy. After removing Teoc groups from $\mathbf{2 3}$ and $\mathbf{2 5}$ using TBAF, each amine-functionalized hexamer $\mathbf{2 4}$ and $\mathbf{2 6}$ was reacted separately with diacid $\mathbf{2 7}$ using PyBOP as coupling agent to yield Boc protected capsules $\mathbf{2 8}$ and $\mathbf{2 9}$, respectively (Scheme 2). Side-chain deprotection was carried out with TFA in dichloromethane and the resulting water soluble oligomers 3 and 4 were purified by reversed-phase HPLC (C18) prior to physicochemical studies.

Recognition in presence of a polar aprotic solvent. To compare with the binding properties of $\mathbf{1}$ for D/L-tartartic acid $\mathbf{5}$ in $\mathrm{CDCl}_{3}:\left[\mathrm{D}_{6}\right]-\mathrm{DMSO} 90: 10$ ( $\left.\mathrm{vol} / \mathrm{vol}\right)$, the efficacy of capsule 2 was assessed by ${ }^{1} \mathrm{H}$ NMR titrations in the same medium. As previously observed for the encapsulation of $D / L-5$ in $1,{ }^{16 c}$ the addition of the guest to capsule 2 led to the emergence of a new set of sharp signals indicating slow exchange on the NMR time scale between empty host 2 and host-guest complex $2 \supset D / L-5$ (Figure 2). At low field (14 ppm), one can distinguish the sharp resonance of the hydrogen-bonded carboxylic acid protons of the guest. Through the integration of the signals of free $\mathbf{2}$ and $2 \supset \mathrm{D} / \mathrm{L}-\mathbf{5}$ an affinity constant $\left(K_{a}\right)$ was calculated to be $2.910^{4} \mathrm{~L}$ $\mathrm{mol}^{-1}$ at $298 \mathrm{~K}$ in this solvent. This is considerably higher than the value previously observed for $1\left(5.310^{3} \mathrm{~L} \mathrm{~mol}^{-1}\right) .{ }^{16 c}$ The double $\mathbf{P} \rightarrow \mathbf{F}$ mutation thus led to an increase of $K_{a}$ by almost 6 fold, even though $\mathbf{P}$ units do not appear to be directly involved in tartaric acid binding in the structure of $\mathbf{1} \supset \mathbf{5} .{ }^{16 c}$ Compared to $\mathbf{P}$ units, $\mathbf{F}$ units feature an exocyclic fluorine atom pointing towards the capsule cavity that fills a small void of the structure of $\mathbf{1} \supset \mathbf{5}$. Presumably, the polarity of fluorine atoms also comes into play in a favourable way, similar to what was observed in the binding of monosaccharides. ${ }^{16 d}$

However, when the proportion of $\left[\mathrm{D}_{6}\right]$-DMSO was increased to 20\% ( $\mathrm{vol} / \mathrm{vol})$, association of $\mathbf{5}$ to $\mathbf{1}$ and $\mathbf{2}$ dropped to similar levels ( $K_{a}$ of 750 and $910 \mathrm{~L} \mathrm{~mol}^{-1}$, respectively, see Table 1 ). The addition of a polar aprotic solvent thus has a more pronounced effect on binding within 2 .

The effect of methanol on binding. Intrigued by these results, we set to explore the behaviour of capsules $\mathbf{3}$ and $\mathbf{4}$, the analogues of $\mathbf{1}$ and $\mathbf{2}$, respectively, bearing charged side chains, and the extent to which slight modifications ( $\mathbf{P} v s$. F) of the sequence may alter or favour the binding of a guest in protic organic solvents and water. We first assessed the affinity of receptor $\mathbf{3}$ and $\mathbf{4}$ for tartaric acid in $\mathrm{CD}_{3} \mathrm{OH}$, a solvent that strongly competes with hydrogen bond formation between host and guest. In this medium, both $\mathbf{3}$ and $\mathbf{4}$ exhibit good solubility. The absence of non-specific aggregation is supported by sharp ${ }^{1} \mathrm{H}$ NMR signals. Upon increasing the concentration of $\mathbf{5}$ in a $\mathrm{CD}_{3} \mathrm{OH}$ solution of $\mathbf{3}$ or $\mathbf{4}$, free host resonances were again replaced by a new single set of sharp signals (Figure 3 ), consistent with slow exchange on the NMR time scale and showing that a single diastereomeric complex is formed (d.e. > 99\%) in protic solvents as well. NMR spectra indicated that the guest carboxylic acid groups were strongly hydrogen-bonded (resonance above 15 ppm, Figure 3 ) though signals were slightly broader than for similar complexes in chloroform-DMSO mixtures.

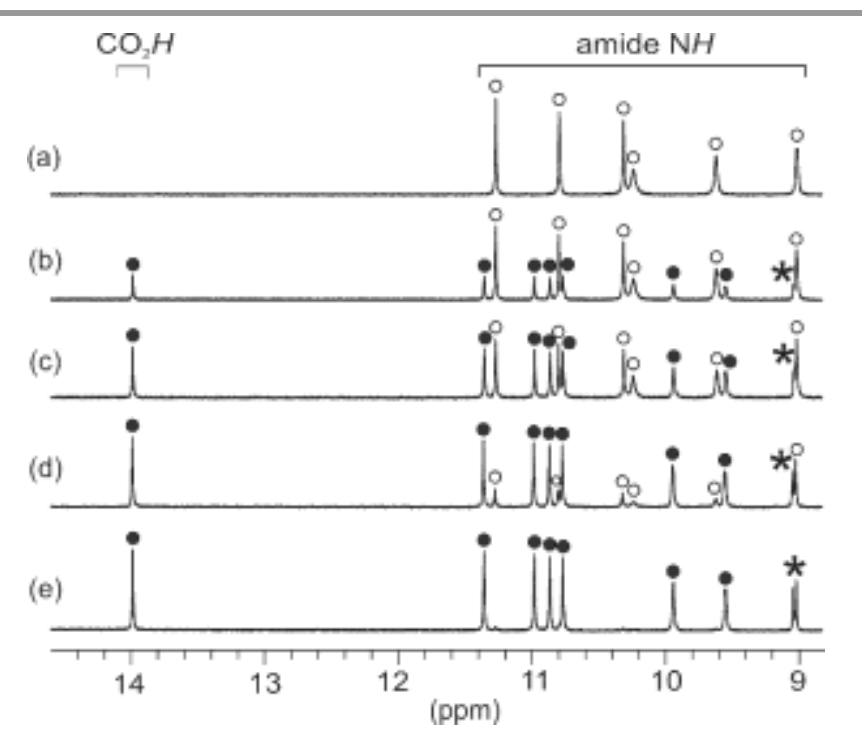

Fig. 2 Excerpts of the $400 \mathrm{MHz}^{1} \mathrm{H}$ NMR spectra of capsule $\mathbf{2}(1 \mathrm{~mm})$ at $298 \mathrm{~K}$ in the presence of: (a) 0 equiv.; (b) 0.25 equiv.; (c) 0.5 equiv. and (d) 1 equiv.; (e) 2 equiv. of $\mathrm{D} / \mathrm{L}-5$ in a mixture of $\mathrm{CDCl}_{3}:\left[\mathrm{D}_{6}\right]-\mathrm{DMSO}(90: 10 \mathrm{vol} / \mathrm{vol})$. Signals of the empty host and of the host-guest complex are denoted in empty and black circles, respectively. The carboxylic acid resonance of the bound guest can be observed at low field (14 ppm). Stars $\left(^{*}\right)$ denote aromatic resonances.

Table 1. Association constants $\left(K_{a}\right)$ and thermodynamic parameters for $1: 1$ host-guest complexes for caspules 1, 2, 3 and $\mathbf{4}$ with $\mathrm{D} / \mathrm{L}$ tartaric acid $\mathbf{5}$ in organic solvents and water at $298 \mathrm{~K}$, as measured by ${ }^{1} \mathrm{H}$ NMR and ITC.

\begin{tabular}{|c|c|c|c|c|}
\hline Complex / solvent mixture & $\begin{array}{l}K_{a} \\
{\left[\mathrm{M}^{-1}\right]}\end{array}$ & $\begin{array}{l}\Delta \mathrm{H} \\
{\left[\mathrm{kJ} \mathrm{mol}^{-1}\right]}\end{array}$ & $\begin{array}{l}\mathrm{T} \Delta \mathrm{S} \\
{\left[\mathrm{kJ} \mathrm{mol}^{-1}\right]}\end{array}$ & $\begin{array}{l}\Delta \mathrm{G} \\
{\left[\mathrm{kJ} \mathrm{mol}^{-1}\right]}\end{array}$ \\
\hline $\mathbf{5} \subset \mathbf{1} / \mathrm{CDCl}_{3}: \operatorname{DMSO}(9: 1)$ & $5300^{\mathrm{a}}$ & n.d. & n.d. & n.d. \\
\hline $\mathbf{5} \subset \mathbf{2} / \mathrm{CDCl}_{3}: \operatorname{DMSO}(9: 1)$ & $29000^{\mathrm{a}}$ & n.d. & n.d. & n.d. \\
\hline $\mathbf{5} \subset \mathbf{1} / \mathrm{CDCl}_{3}: \operatorname{DMSO}(8: 2)$ & $750^{\mathrm{a}}$ & $-16.7^{\mathrm{a}}$ & $-0.5^{\mathrm{a}}$ & $-16.3^{\mathrm{a}}$ \\
\hline $\mathbf{5} \subset \mathbf{2} / \mathrm{CDCl}_{3}: \mathrm{DMSO}(8: 2)$ & $910^{\mathrm{a}}$ & $-25.2^{\mathrm{a}}$ & $-8.6^{\mathrm{a}}$ & $-16.6^{\mathrm{a}}$ \\
\hline \multirow[t]{2}{*}{$\mathbf{5} \subset \mathbf{3} / \mathrm{MeOH}$} & $2000^{\mathrm{a}}$ & $-7.3^{\mathrm{a}}$ & $11.4^{\mathrm{a}}$ & $-18.8^{\mathrm{a}}$ \\
\hline & $2660^{\mathrm{b}}$ & $-9.7^{\mathrm{b}}$ & $9.9^{\mathrm{b}}$ & $-19.5^{\mathrm{b}}$ \\
\hline $\mathbf{5} \subset \mathbf{3} / \mathrm{H}_{2} \mathrm{O}: \mathrm{D}_{2} \mathrm{O}(9: 1)$ & $20^{\mathrm{a}}$ & n.d. ${ }^{\mathrm{c}}$ & n.d. ${ }^{\mathrm{c}}$ & n.d. ${ }^{\mathrm{c}}$ \\
\hline \multirow[t]{2}{*}{$5 \subset \mathbf{4} / \mathrm{MeOH}$} & $200^{\mathrm{a}}$ & n.d. & n.d. & n.d. \\
\hline & $280^{\mathrm{b}}$ & $-15.9^{\mathrm{b}}$ & $-2.0^{\mathrm{b}}$ & $-13.9^{b}$ \\
\hline $\mathbf{5} \subset \mathbf{4} / \mathrm{H}_{2} \mathrm{O}: \mathrm{D}_{2} \mathrm{O}(9: 1)$ & $<1^{\mathrm{a}}$ & n.d. ${ }^{\mathrm{c}}$ & n.d. ${ }^{\mathrm{c}}$ & n.d. ${ }^{\mathrm{c}}$ \\
\hline
\end{tabular}

a measured by ${ }^{1} \mathrm{H}$ NMR ; ${ }^{b}$ measured by ITC; ${ }^{c}$ affinity is too low for an accurate determination of the thermodynamic parameters; n.d.: not determined. 

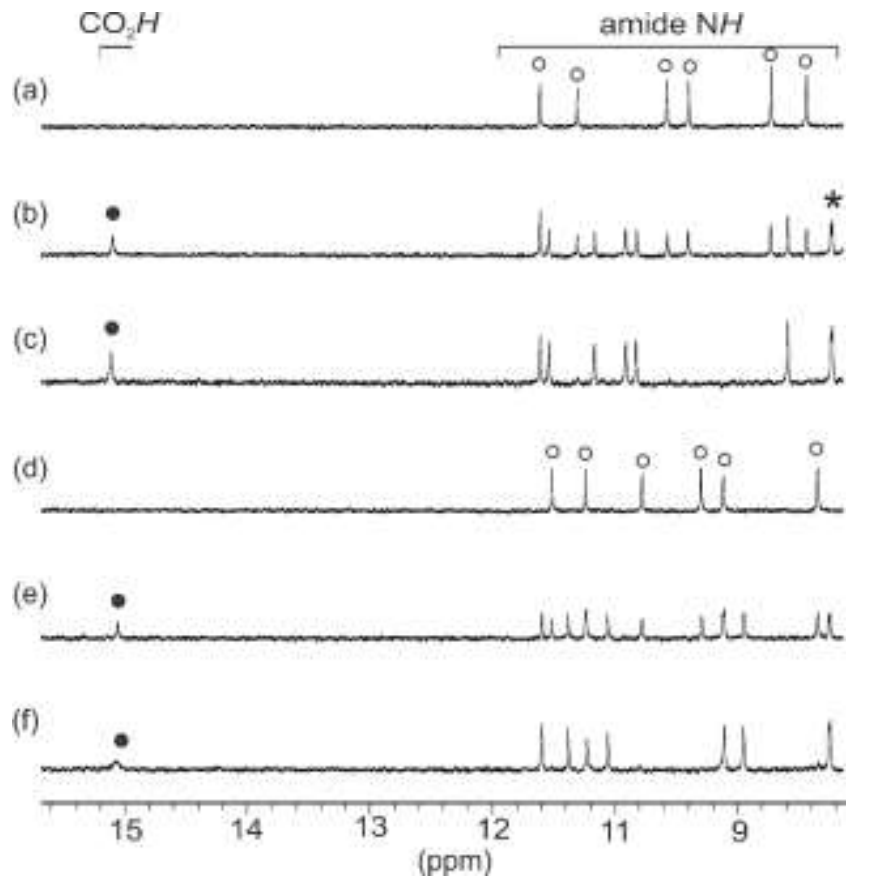

Fig. 3 Excerpts of the $700 \mathrm{MHz}{ }^{1} \mathrm{H}$ NMR spectra of capsule $3(0.25 \mathrm{~mm})$ at $298 \mathrm{~K}$ in the presence of: (a) 0 equiv.; (b) 4.5 equiv.; (c) 30 equiv. of $\mathrm{D} / \mathrm{L}-5$ in $\mathrm{CD}_{3} \mathrm{OH}$. In the same conditions, ${ }^{1} \mathrm{H}$ NMR spectra of capsule 4 in the presence of: (d) 0 equiv.; (e) 15 equiv.; (f) 135 equiv. of $D / L-5$. Signals of the empty host and of the host-guest complex are denoted with empty and black circles, respectively. The carboxylic acid resonance of the bound guest can be observed at low field ( $15 \mathrm{ppm})$. Stars $(*)$ denote aromatic resonances.
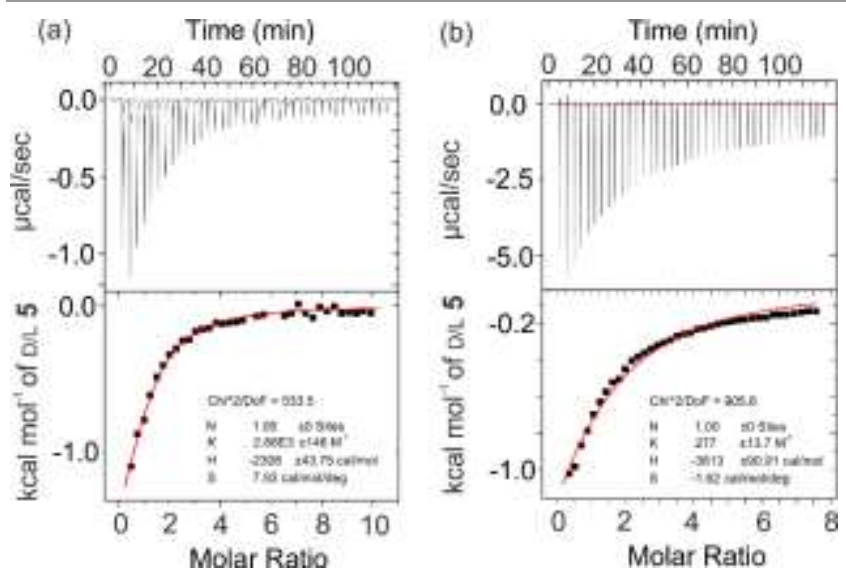

Fig. 4 Raw data (top) and integrated heat pulse data (bottom) of ITC binding studies on: (a) capsule 3 and (b) capsule 4 with D/L-5 in methanol at $298 \mathrm{~K}$. Both analyses constitute a differential binding curve that may be fitted to a $1: 1$ binding model (red line) to give thermodynamics parameters.

The association constant of capsule 3 to $\mathrm{D} / \mathrm{L}-\mathbf{5}$ in $\mathrm{CD}_{3} \mathrm{OH}$ was calculated to be $2000 \mathrm{~L} \mathrm{~mol}^{-1}$ from the proportions of bound vs. unbound species, as measured by integration of the corresponding amide NMR signals (Table 1). As could be expected, $K_{\mathrm{a}}$ values decrease as solvent polarity increases. Nevertheless, the decrease remained modest as $K_{a}$ was lowered by a factor of only 2.7 compared to the value measured for 1 in $\mathrm{CDCl}_{3}:\left[\mathrm{D}_{6}\right]$-DMSO 90:10 ( $\left.\mathrm{vol} / \mathrm{vol}\right)$. For capsules $\mathbf{1}$ and $\mathbf{3}$, methanol thus appears to be less detrimental to binding than DMSO, and the effect of neither polar solvents is dramatic. In contrast, the affinity of $\mathbf{4}$ towards $\mathbf{5}$ in methanol was shown to collapse to $200 \mathrm{~L} \mathrm{~mol}^{-1}$, i.e. two orders of magnitude lower than the affinity of 2 in $\mathrm{CDCl}_{3}:\left[\mathrm{D}_{6}\right]$-DMSO 90:10 (vol/vol). This confirms that the effect of polar solvents on binding by $\mathbf{2}$ and $\mathbf{4}$ is higher.

In addition to NMR measurements, association constants were also determined by Isothermal Titration Calorimetry (ITC, Figure 4). With both methods, data gave excellent fits to a 1:1 binding model and calculated $K_{a}$ values were consistent with NMR data (Table 1). The differential effect of polar protic and aprotic solvents on $\mathbf{1}$ and $\mathbf{3}$ on the one hand, and $\mathbf{2}$ and $\mathbf{4}$ on the other hand, is remarkable as the only difference between the two pairs concerns features located within the host cavities. Guest solvation/desolvation being identical, one must infer that 2 and 4 possess a more polar interior that interacts more favourably with polar molecules, that is, with tartaric acid, and also with polar solvents.

Binding in water. Guest encapsulation within $\mathbf{3}$ and $\mathbf{4}$ was also investigated by ${ }^{1} \mathrm{H}$ NMR titrations in water. Varying the concentration of D/L-5 in a solution of receptor $\mathbf{3}$ dissolved in water led to the appearance of a new set of signals corresponding to the formation of complex 3つD/L-5 (Figure 5) with complete diastereoselectivity (d.e. $>99 \%$ ). Yet binding was weak and saturation was not reached even in the presence of $250 \mathrm{~mm}$ of 5. Furthermore, no signals could be observed at 14 ppm for the carboxylic acid group of the bound guest, possibly because of the exchange with the free guest in large excess. Integration of ${ }^{1} \mathrm{H}$ NMR signals of the free vs. bound capsule allowed us to determine a $K_{a}$ of around $20 \mathrm{~L} \mathrm{~mol}^{-1}$, about two orders of magnitude lower than in methanol. A similar experiment conducted with receptor 4 only revealed trace amount of $4 \supset \mathrm{D} / \mathrm{L}-5$ complex $\left(K_{a}<1 \mathrm{~L} \mathrm{~mol}^{-1}\right)$, again corresponding to a drop of at least two order of magnitude with respect to methanol. Water was thus found to be highly detrimental to binding.

Fig. 5 Excerpts of the $300 \mathrm{MHz}{ }^{1 \mathrm{H}} \mathrm{NMR}$ spectra of capsule 3 (1 mM) at $298 \mathrm{~K}$ in the
presence of: (a) 0 equiv.; (b) 10 equiv.; (c) 40 equiv. and (d) 250 equiv. of D/L-5 in
a $\mathrm{H}_{2} \mathrm{O} \mathrm{D}_{2} \mathrm{O}$ (90:10 vol/vol) mixture. Signals of the empty host and of the host-guest
complex are denoted in empty and black circles, respectively.

Thermodynamics of the encapsulation process. To deepen our understanding of the encapsulation, we investigated the thermodynamic parameters of tartaric acid binding by capsules 
1 and 2 in $\mathrm{CDCl}_{3}:\left[\mathrm{D}_{6}\right]-\mathrm{DMSO} 80: 20$ (vol/vol). With this proportion of DMSO, $K_{a}$ values fall in a range that can be very accurately measured using ${ }^{1} \mathrm{H}$ NMR. Temperature was increased from $278 \mathrm{~K}$ to $328 \mathrm{~K}$, leading to progressive host-guest complex dissociation. Linear van't Hoff plots (Figure S1-S2) showed that encapsulation of $\mathbf{5}$ in both $\mathbf{1}$ and $\mathbf{2}$ is enthalpy driven (strong negative $\Delta \mathrm{H}$ values, Table 1$)$. Nevertheless, similar $K_{a}$ values in fact hide distinct thermodynamic parameters. The enthalpic term was found to be more favourable in the case of $\mathbf{2}(\Delta \mathrm{H}=-$ 25.2 , vs $-16.7 \mathrm{~kJ} \mathrm{~mol}^{-1}$ for 1 ), revealing stronger, presumably polar, interactions with tartaric acid. This is consistent, with the very high binding observed upon decreasing the proportion of DMSO down to $10 \%$, and also with the overall higher effects of polar solvents on binding to $\mathbf{2}$ as opposed to $\mathbf{1}$. As the cavity of $\mathbf{2}$ is more polar, not only tartaric acid binding but also competitive solvent binding is more efficient. Not surprisingly, the large enthalpic term of binding by $\mathbf{2}$ is compensated by an unfavourable entropic term (-T $\Delta \mathrm{S}=8.6 \mathrm{~kJ} \mathrm{~mol}^{-1}$ at $\left.298 \mathrm{~K}\right)$. In contrast, binding entropy by sequence $\mathbf{1}$ is very small. The enthalpy-entropy compensation observed for $\mathbf{2}$ is typical ${ }^{8,20}$ and reflects the fact that, for all favourable interactions to be established upon binding tartaric acid in the cavity of $\mathbf{2}$, the complex geometry has to be more restricted than upon binding to 1 .

We also investigated the thermodynamics of tartaric acid encapsulation by capsules $\mathbf{3}$ and $\mathbf{4}$ in methanol. In this solvent, binding constants were sufficiently high to use ITC. In the case of 3, thermodynamic parameters extracted from ITC were corroborated by a van't Hoff plot of variable temperature NMR data (Table 1, Figure S3). Similar to what was observed in chloroform-DMSO for capsules $\mathbf{1}$ and 2, binding in methanol went with favourable enthalpy, this term being more favourable in the case of $4\left(\Delta \mathrm{H}=-15.9 \mathrm{~kJ} \mathrm{~mol}^{-1}\right)$ than for $3(-9.7$ $\left.\mathrm{kJ} \mathrm{mol}^{-1}\right)$. However, both terms were significantly smaller than in chloroform-DMSO mixtures, reflecting the better ability of methanol to solvate both the host and guest and the overall weaker binding in this solvent. The values of entropic terms in methanol for $\mathbf{3}$ and $\mathbf{4}$ differed significantly from those observed in chloroform-DMSO. Indeed, the binding of tartaric acid to capsule $\mathbf{3}$ was found to have a strongly favourable entropic term (-TAS $=-9.9 \mathrm{~kJ} \mathrm{~mol}^{-1}$ at $\left.298 \mathrm{~K}\right)$. This effect appeared to be characteristic of the solvent and not of a change in the binding itself, and was assigned to the favorable release of encapsulated methanol molecules from the helical capsule upon binding tartaric acid. Encapsulation by $\mathbf{3}$ in methanol is thus both enthalpically and entropically driven. The favorable entropic solvent effects also operated for capsule 4 but, since the binding entropy was inherently less favorable, as explained above for $\mathbf{2}$, the outcome was a weakly unfavourable entropic effect (-TAS $=2.0 \mathrm{~kJ} \mathrm{~mol}^{-1}$ at $298 \mathrm{~K}$ ).

Similar experiments using ITC or NMR could not be conducted in water due to the low affinity of both receptors 3 and $\mathbf{4}$ in this medium. By extrapolation of the results observed in methanol, one may expect enthalpic term to further decrease to due competitive binding of both hosts and guest by the solvent. If any solvent-derived favourable entropic effect occurs in water, as for methanol, it is too weak to compensate for the weak enthalpy.

\section{Conclusions}

In conclusion, we have shown that tartaric acid binding by two related foldamer sequences is strong enough to be observed in polar and in protic media such as methanol, or chloroformDMSO mixtures. Binding of this polar guest in water was considerably weaker. Sequences $\mathbf{2}$ and $\mathbf{4}$ show stronger interactions with tartaric acid than sequences $\mathbf{1}$ and $\mathbf{3}$, as expressed by a more negative binding enthalpy. These stronger, presumably more polar, interactions lead to higher binding when decreasing solvent polarity. However, the same interactions are more susceptible to competitive binding by polar solvents, eventually leading to lower affinity in protic medium. To achieve binding in water, one may thus not rest only on polar groups and hydrogen bonding. In a classical manner, stronger interactions were found to be partly compensated by unfavourable entropic effects.

An interesting case of solvent-induced entropically driven binding in methanol was observed. One may expect that such favourable solvent effects become stronger for larger capsule designs whose cavity would release multiple solvent molecules upon guest binding. Current efforts are being made in this direction in our laboratories and will be reported in due course.

\section{Acknowledgements}

This work was supported by grant ANR-09-BLAN-0082-01 (postdoctoral fellowship to for N.C.), a fellowship from the French embassy in Egypt (\#787537A to M.F.E.-B.), the Conseil Interprofessionnel du Vin de Bordeaux (predoctoral fellowship to G.L.) and by the European Research Council under the European Union's Seventh Framework Programme (grant agreement no. ERC-2012-AdG-320892, post-doctoral fellowship to G.L.).

\section{Notes and references}

1 (a) E. A. Kataev, C. Müller, Tetrahedron, 2014, 70, 137; (b) A. Dalla Cort, G. Forte, L. Schiaffino, J. Org. Chem., 2011, 76, 7569; (c) A. P. Davis, Nature, 2010, 464, 169; (d) S. Kubik, Chem. Soc. Rev., 2008, 38, 585; (e) G. V. Oshovsky, D. N. Reinhoudt, W. Verboom, Angew. Chem. Int. Ed., 2007, 46, 2366; (f) E. A. Meyer, R. K. Castellano, F. Diederich, Angew. Chem. Int. Ed., 2003, 42, 1210.

2 (a) S. M. Liu, H. Y. Gan, A. T. Hermann, S. W. Rick, B. C. Gibb, Nat. Chem., 2010, 2, 847; (b) C. L. D. Gibb, B. C. Gibb, J. Am. Chem. Soc., 2004, 126, 11408; (c) L. S. Kaanumalle, C. L. D. Gibb, B. C. Gibb, V. Ramamurthy, J. Am. Chem. Soc., 2005, 127, 3674; (d) L. Trembleau, J. Rebek Jr., Science, 2003, 301, 1219.

3 (a) G. Huber, T. Brotin, L. Dubois, H. Desvaux, J. P. Dutasta, P. Berthault, J. Am. Chem. Soc., 2006, 128, 6239; (b) C. Hilty, T. J. Lowery, D. E. Wemmer, A. Pines, Angew. Chem. Int. Ed., 2006, 45, 70; (c) E. L. Piatnitski, R. A. Flowers, K. Deshayes, Chem. Eur. J., 2000, 6, 999.

4 (a) F. Corbellini, L. Di Costanzo, M. Crego-Calama, S. Geremia, D. N. Reinhoudt, J. Am. Chem. Soc., 2003, 125, 9946; (b) F. Corbellini, R. Fiammengo, P. Timmerman, M. Crego-Calama, K. Versluis, A. J. R. Heck, I. Luyten, D. N. Reinhoudt, J. Am. Chem. Soc., 2002, 124, 6569.

5 (a) A. V. Davis, K. N. Raymond, J. Am. Chem. Soc., 2005, 127, 7912; (b) C. Sgarlata, J. S. Mugridge, M. D. Pluth, B. E. F. Tiedemann, V. Zito, G. Arena, K. N. Raymond, J. Am. Chem. 
Soc., 2010, 132, 1005; (c) M. Yoshizawa, J. Nakagawa, K. Kumazawa, M. Nagao, M. Kawano, T. Ozeki, M. Fujita, Angew. Chem. Int. Ed., 2005, 44, 1810; (d) T. Sawada, M. Yoshizawa, S. Sato, M. Fujita, Nat. Chem., 2009, 1, 53; (e) J. L. Bolliger, T. K. Ronson, M. Ogawa, J. R. Nitschke, J. Am. Chem. Soc., 2014, 136, 14545; (f) P. Mal, D. Schultz, K. Beyeh, K. Rissanen, K.; J. R. Nitschke, Angew Chem. Int. Ed., 2008, 47, 8297; (g) M. Yamashina, Y. Sei, M. Akita, M. Yoshizawa, Nat. Commun. 5, 4662.

6 M. Rekharsky, Y. Inoue, J. Am. Chem. Soc., 2000, 122, 10949.

7 (a) A. McCurdy, L. Jimenez, D. A. Stauffer, D. A. Dougherty J. Am. Chem. Soc., 1992, 114, 10314; (b) S. B. Ferguson, E. M. Sanford, E. M. Seward, F. Diederich, J. Am. Chem. Soc., 1991, 113, 5410.

8 K. N. Houk, A. G. Leach, S. P. Kim, X. Y. Zhang, Angew. Chem Int. Ed., 2003, 42, 4872

9 E. Klein, Y. Ferrand, N. P. Barwell, A. P. Davis, Angew. Chem. Int. Ed., 2008, 47, 2693.

10 (a) S. H. Gellman, Acc. Chem. Res., 1998, 31, 173; (b) G Guichard, I. Huc, Chem. Commun., 2011, 47, 5933.

11 (a) D.-W. Zhang, X. Zhao, J.-L. Hou, Z.-T. Li, Chem. Rev., 2012 112, 5271; (b) I. Saraogi, A. D. Hamilton, Chem. Soc. Rev., 2009, 38, 1726; (c) I. Huc, Eur. J. Org. Chem., 2004, 17; (d) T. Nishinaga, A. Tanatani, K. Oh, J. S. Moore, J. Am. Chem. Soc. 2002, 124, 5934; (e) A. Tanatani, T. S. Hughes, J. S. Moore Angew. Chem. Int. Ed., 2002, 41, 325; (f) K.-J. Chang, B.-N. Kang, M.-H. Lee, K.-S. Jeong, J. Am. Chem. Soc., 2005, 127 12214; (g) M. Waki, H. Abe, M. Inouye, Angew. Chem. Int. Ed. 2007, 46, 3059; (h) H. Abe, H. Machiguchi, S. Matsumoto, M. Inouye, J. Org. Chem., 2008, 73, 4650; (i) Y. Hua, A. H. Flood, J. Am. Chem. Soc., 2010, 132, 12838; (j) Y. Wang, F. Bie, H. Jiang, Org. Lett., 2010, 12, 3630.

12 T. Qi, V. Maurizot, H. Noguchi, T. Charoenraks, B. Kauffmann, M. Takafuji, H. Ihara, I. Huc, Chem. Commun., 2012, 48, 6337.

13 (a) A. M. Abramyan, Z. Liu, Vojislava Pophristic Chem. Commun., DOI: 10.1039/C5CC07060K; (b) Z. Liu, A. M. Abramyan, V. Pophristic, New J. Chem., 2015, 39, 3229.

14 (a) B. Gong, H. Zeng, J. Zhu, L. Yuan, Y. Han, S. Cheng, M. Furukawa, R. D. Parra, A. Y. Kovalevsky, J. L. Mills, E. Skrzypczak-Jankun, S. Martinovic, R. D. Smith, C. Zheng, T. Szyperski, X. Cheng Zeng, Proc. Natl. Acad. Sci. USA, 2002, 99, 11583; (b) J.-L. Hou, X.-B. Shao, G.-J. Chen, Y.-X. Zhou, X.-K. Jiang, Z.-T. Li, J. Am. Chem. Soc., 2004, 126, 12386; (c) C. Li, G.T. Wang, H.-P. Yi, X.-K. Jiang, Z.-T. Li, R.-X. Wang, Org. Lett., 2007, 9, 1797; (d) Q. Gan, Y. Ferrand, C. Bao,; B. Kauffmann, A. Grélard, H. Jiang, I. Huc, Science, 2011, 331, 1172; (e) Y. Ferrand, Q. Gan, B. Kauffmann, H. Jiang, I. Huc, Angew. Chem. Int. Ed. 2011, 50, 7572; (f) L.-Y. You, Chen, S.-G.; X. Zhao, Y. Liu, W.-X. Lan, Y. Zhang, H.-J. Lu, C.-Y. Cao, Z.-T. Li Angew. Chem., Int. Ed., 2012, 51, 1657; (g) Q. Gan,; Y. Ferrand, N. Chandramouli, B. Kauffmann, C. Aube, D. Dubreuil, I. Huc, J. Am. Chem. Soc., 2012, 134, 15656.

15 (a) J. Garric, J.-M. Léger, I. Huc, Angew. Chem. Int. Ed., 2005, 44, 1954; (b) Y. Hua, Y. Liu, C-H. Chen, A. H. Flood, J. Am. Chem. Soc., 2013, 135, 14401.

16 (a) C. Bao, B. Kauffmann, Q. Gan, K. Srinivas, H. Jiang, I. Huc, Angew. Chem. Int. Ed., 2008, 47, 4153; (b) C. Bao, Q. Gan, B. Kauffmann, H. Jiang, I. Huc, Chem. Eur. J., 2009, 15, 11530; (c) Y. Ferrand, A. M. Kendhale, B. Kauffmann, A. Grélard, C. Marie, V. Blot, M. Pipelier, D. Dubreuil, I. Huc, J. Am. Chem Soc., 2010, 132, 7858; (d) N. Chandramouli, Y. Ferrand, G. Lautrette, B. Kauffmann, C. D. Mackereth, M. Laguerre, D. Dubreuil, I. Huc, Nat. Chem., 2015, 7, 334.

17 (a) Y. Ferrand, N. Chandramouli, A. M. Kendhale, C. Aube, B Kauffmann, A. Grélard, M. Laguerre, D. Dubreuil, I. Huc J. Am. Chem. Soc., 2012, 134, 11282; (b) A. M. Abramyan, Z. Liu and V. Pophristic, Phys. Chem. Chem. Phys., 2014, 16, 20406.
18 F. Garcia-Tellado, S. J. Geib, S. Goswami, A. D. Hamilton, J. Am. Chem. Soc., 1991, 113, 9265.

19 E. Gillies, F. Deiss, C. Staedel, J.-M. Schmitter, I. Huc, Angew. Chem. Int. Ed., 2007, 46, 4081.

20 C.-E. Chang, M. K. Gilson, J. Am. Chem. Soc., 2004, 126, 13156 